\title{
Media Literacy: An Analysis of Social Media Usage among Millennials
}

\author{
Rizki Briandana, Nindyta Aisyah Dwityas
}

\author{
Faculty of Communication Sciene, Universitas Mercu Buana, Jakarta-Indonesia
}

\begin{abstract}
Fast technological development has impact to smartphone technology. The smartphone users unconsciously become dependent to the technology. Media literacy to adolescents is important and it will give critical analysis in the access of media messages and create messages by using the media. This research aims at knowing media literacy to the uses of social media (Facebook and Instagram) among adolescents in South Tangerang. Theory of Media Literacy from James Potter was used as the main concept in the research. It used quantitative approach with positivism paradigm and survey research method. The data collection was used through questionnaire with purposive sampling technique which was defined as the sampling method. The research findings indicate that media literacy level among adolescents bases on the Individual Competence Framework that consists of three indicators: media literacy level on the basis of Use Skill, and it gets average value of 36.38 for $60.93 \%$ of the respondents. It includes the medium category in the Critical Understanding indicators and it has average value of 47.85 from $51.72 \%$ of the respondents and it includes the medium category in the indicators of Communicative Abilities it gets average value of 27.34 from $59.77 \%$ of the respondents and it includes the medium category.
\end{abstract}

Keywords - media literacy, social media, adolescents, Individual Competence

\section{INTRODUCTION}

Technology changes fast in the world, and it has a significant impact to human life. A fast technological development particularly relates to smartphones. Many smartphone companies are competing each other in product innovation with sophisticated features and technology. These competing companies are Samsung from Korea, iPhone from United States of America, Sony from Japan, Oppo and Lenovo from China and others [1].

As an electronic media, smartphones can have great influence to the life of individuals, families and society [2]. If compared to other media in this time, smartphone uses dominantly have a great attraction to millennial teenagers. Besides having many features, smartphones can be easily carried to anywhere. With the existence of smartphones that are equipped with internet facilities, people easily obtain the intended information online.
Therefore, the need for entertainment, information and education can be fulfilled with the presence of internet media [3].

Smartphones are a media device and these are more popular among adolescents today. Based on the results of a survey conducted by the Ministry of Communication and Information of the Republic of Indonesia, it shows that adolescents are the age group with the highest internet access. For adolescents, smartphones become a part of their lives. With the support of internet access from certain providers, they can access the required information and communicate in various directions with different destinations; therefore, it gets some of them addicted to smartphones [4]. Almost every adolescent has had a smartphone communication tool. A few of them can have more than one smartphone [5]. All this relates to globalization. Globalization makes the world of technology fastest growing. With the development of technology and all the sophistication that a smartphone has, it makes many adolescents amazing and they want to have it [6].

Dogruel, Joeckel, \& Bowman (2015) shows that the Internet use behavior among adolescents in urban area is more directerd to leisure/fun activities than other interests, such as information utility, communication and transactions. Moreover, according to Giles (2010), excessive Internet uses excessively lead to the interest of social relationship than information collection. It becomes the power of attraction for the Internet uses and it gives a very high influence to the life of individuals, families and communities.

Recently, Internet media particularly the uses of social media closely relate to daily social activities. Socities compete each other to get sensation so that they can get the intended attention. It is undeniable that advances in technology make change, technology changes, human changes, time changes and the world changes [9]. Social media is an online media that the users can communicate and interact each other for information exchange and networking.

There are many popular social media used in Indonesia. Social Network is a social interaction because websites have facilities to make interaction and exchange of opinions and comments. It also includes blogs, online 
forums, chat applications such as email, chat, short message. It can refer to websites or applications such as Facebook, Twitter, Path, Tumbler, Pinterest, Instagram [10].

The old social media that remain exist until the present day among adolescents are Facebook and Instagram, for example. Almost every adolescent have Facebook and Instagram accounts right now (Adiarsi et al., 2015). Facebook and Instagram provide some great facilities. For example, on Facebook we can make messenger, group services, Photo Albums, selling and buying groups, Special Event Services, Update Status Service, Facebook Gift for sending gift to your friends, Facebook friends. Moreover, on Instagram we can update on timeline fast, unlimited friendship, photo and video uploading. Many noblemen have social media accounts as well [11].

Facebook and Instagram provide, there are negative effects particularly for adolescents who spend a lof of their time to use the Internet on social media networks such as Facebook and Instagram than learning [2]. For easy to make communication and get information required in fast, it gives addiction's effect so that adolescents will access Internet with an unrestricted time limit. From the assumption, education and understandings on media uses have to be definitely considered [7]. Particularly in this research they are adolescents who frequently access Internet to make relationship, look for information and fulfill their curiosity. Understanding on the media uses are called media literacy.

Media literacy can be stated as a process to access, analyze media messages critically and make messages that use media tools. Hobbs (2017) explains that the meaning of media literacy is to understand sources, communication technology, codes that are used in the process, messages that come from selection, interpretation and effects of the messages. Therefore, it can be stated that Internet or new media make communication patterns and lifestyle change. Individuals are not only in the position as media customers but also as producers.

The skill of media literary particularly Internet media is a must that adolescents should have if they will not be left behind and become strange in an environment that have been hit with the flow of digital information [9]. It is expected that media literacy among adolescents particularly in the uses of Internet media can wisely use Internet media to increase and expand their vision and reduce negative effects from the uses and information so that it is avoidable with negative things, such as consumerism, violence culture, peep culture towards others' privacy, faster sexual maturity that occurs for children age.
Based on the above description, ideas on the media literacy of Internet among adolescents as social media users becomes an interesting thing to be studied. Those who become the research respondents are adolescents or students who remain studying in some vocational high schools, i.e. SMK Negeri I, SMK Negeri 2 and SMK Negeri 3 in Tangerang. The justification of selecting these vocational high schools will refer to the data of Ministry of Education and Culture, these schools have achieved the status of the integrating school, i.e. the schools that successfully have gotten high score in the national achievement test and the student's education achievements. The research describes how the media literacy among adolescents as the Internet users particularly those who have access through smartphones when they criticize media content to be read or consumed.

\section{CONCEPTUAL FRAMEWORK OF THE STUDY}

\section{Internet Media Communication}

Internet is a new medium that converges all media characteristics from earlier forms [1]. What makes communication forms different to each other is not actual implementation but change in communication process such as communication speed, communication prices, perception to the parties who make communication, storage capacity and facilities to access information, the amount of functionality or intelligence that can be transferred.

Computer mediated communication is the concept and study area that relatively remain new and few parties do not discuss a lot [12]. Some Internet media explorations contributes to the terminology of the computer mediated communication. Pixy Ferris generally defines Internet mediated communication as "interpersonal interaction connected by computer networks covers asynchronous and synchronous communcation through facilities on Internet". In the application terminology, finally the Internet mediated communication is the uses of computers that include facilities and its abilities to be utilized as the tools of mass and personal messengers [12].

\section{New Media}

New media is the media that offers digitization, convergence, interactivity and the development of network in relation to the making and sending of messages [13]. The ability to provide interactivity makes new media users capable to have information choices to be consumed as well as control information outputs and carry out the intended choices. The ability to offer an interactivity is the central concept of understanding the new media [14]. 
McQuail in Ardianto (2011) describes that the main characteristics that present the differences between new media and old/conventional media based on the perspective of users are, i.e. (1) Interactivity; It indicates on the ratio of response or initiative from the users against "offer" from source/sender (message), (2) Social presence (sociability); It indicates what the users experience, the sense of personal contacts with others that can be created through the use of a medium. Media richness: the new media can bridge any different frame of reference, reduce ambiguity, give signs, more sensitive and personal, (3) Autonomy; Users feel that they can control the content and how to use it and have independence to source, (4) Playfulness; It is used for entertainment and enjoyment, (5) Privacy; It is associated with the uses of medium and or the chosen content, (6) Personalization; The level where the content and media uses are sensitive and personal [15].

\section{Media Literacy}

Basically the media literacy is the effort of learning for media audience so that they become audience who have vitality in the world called the media saturated people [16]. The media literacy is an education that aims at increasing students' understanding on the way of media work, the way of media production, the way of organizing media and the way of media to construct reality [17]. It also aims at providing skills among adolescents to create media products.

According to Hobbs (2010), the media literacy is the process of accessing, critically analyzing media messages and creating messages using media tools and explains that what we mean the media literacy is understanding resources, communication technology, codes that we have used, messages that we have produced, selection, interpretation and effects of the messages.

The media literacy is a perspective from which we expose ourselves to the media and interpret the meaning of the messages we encounter" [13]. From the above definition, according to Potter's (2018) definition media literacy is a perspective from where we can actively expose ourselves ability to be exposed to media so that it will interpret the meaning of the messages we meet. The media literacy is simply an ability to filter in sorting out and selecting the contents of messages found in printed and electronic media.

In the notes of Potter (2018) there are more than 20 definitions on media literacy. The definitions on media literacy that thinkers have put forward indicate some important statements on media literacy. Firstly, the media literacy encourages the emergence of critical thinking from the public towards the programs that have been presented by the media. Secondly, the media literacy may create the ability to make communication competently in all kinds of media, have a more active attitude than reactive one in understanding media programs [20]. The definition having been formulated by the Alliance for Media Literate America states that the media literacy relates to more critically questioning, learning and developing skills rather than simply blaming media. Another definition having been formulated by Children Now states that the literacy of media is a way to bring watching skills to young audiences critically. The term media is used as the synonym for / or being part of media education [21].

Digital literacy or called digital information literacy is a concept that explains the literacy concept in the digital era (Bawden, 2018). The concept of digital literacy has emerged since 1990. According to Potter (2018), the digital literacy is explained as the ability to understand and use information from various formats. Gilster explains that the literacy concept is not only about the ability to read but also to read with meaning and understanding. The digital literacy includes mastering ideas and not just keystrokes.

Anderson \& Jiang (2018) mentions several reasons for the importance of media education / media literacy. The reasons to hold the media education / media literacy are:

1. We have to be well-informed about media, and why and how information is communicated. Humans have to have the ability to assess reliable information

2. Mass media is an important part of many people's experience so that instead other forms of information and entertainment such as books, we have to study mas s media.

3. It is considered important to provide learning on the experiences of children how to consume media.

4. Mass media is the main source of information and become part of our culture, and therefore, learners should understand how mass media shape meaning

\section{Individual Competence}

Individual Competence is the ability of individuals to use and utilize media. It is among other the skills to use, produce, analyze and communicate messages through media. The Individual Competence is divided into two categories:

1. Personal Competence, i.e. the ability of individuals to use media and analyze media contents.

2. Social Competence, i.e. the ability of individuals to communicate and build social relationship through media and be able to produce media contents.

Personal Competence consists of two criterias: [23]

1. Use skills, i.e. the technique skills to use media. It means that individuals are able to operate media and understand all kinds of instruction in the media. 
2. Critical Understanding, i.e. the cognitive skills to use media such as understanding, analyzing and evaluating media contents.

Social competence consists of Communicative Abilities, i.e. the ability to make communication and participation through media. The Communicative abilities cover the ability to build social relationship and participation in public through media. Moreover, these also include the ability to make and produce media content [23].

The ability of Internet media literacy among adolescents, i.e. the students of the vocational high school (SMKN 1, SMKN 2, SMKN 3) in Tangerang will be measured by using Individual Competence Framework in the Final Report Study on Assessment Criteria for Media Literacy Levels carried out by the European Commission. In the past the framework was used to measure media literacy levels in European Union countries. The measurement that is used in this research bases on Individual Competence. The indicators of the Internet Media Literacy Instrument that have been reviewed by Individual Competence refer to the framework from the European Commission Directorate General Information Society and Media; Media Literacy Unit. The framework as the guidance for the core questions can be applied as the basis of survey to measure the media literacy levels. The researchers apply the framework as the indicators in the survey but make adaptation with the existing circumstances in Indonesia in general and South Tangerang City in specific. Three dimensions used in the research are as follows:

Fig.1: Level Competence

\begin{tabular}{|l|l|}
\hline Level & Definition \\
\hline Basic & $\begin{array}{l}\text { The individual has a set of abilities that } \\
\text { allows basic use of the media. There is a } \\
\text { limited use of media. The user knows its } \\
\text { basic function, deciphers its basic codes } \\
\text { and uses it for specific ends and to } \\
\text { determine the tool. The user's capacity to } \\
\text { critically analyse the information received } \\
\text { is limited. Its communicative capability } \\
\text { through media is also limited. }\end{array}$ \\
\hline Medium & $\begin{array}{l}\text { The individual is fluent in media use, } \\
\text { knowing their functions and able to carry } \\
\text { out certain, more complex operations. The } \\
\text { use of media is extended. The userknows } \\
\text { how to obtain and assess the information } \\
\text { he/she requires, as well as evaluating (and } \\
\text { improving) the information search } \\
\text { strategies. }\end{array}$ \\
\hline Advaned & $\begin{array}{l}\text { The individual is very active in media } \\
\text { use, being aware of and interested in the } \\
\text { legal conditions that affect its use. The }\end{array}$ \\
\hline
\end{tabular}

user has an in-depth knowledge of the techniques and languages and can analyse (and, eventually) transform the conditions affecting his/hercommunicative relations and the creation of messages. In the social sphere, the user is capable of activating cooperation groups that allow him/her to solve problems.

Source : European Commission Directorate General Information Society and Media; Media Literacy Unit, 2009.

To answer three formulas of the research problems at above, the questions or statements that are made in the three parts, i.e. the statement on the Understanding of New Media Function, Media Literacy and Individual Competence that consists of Use Skills, Critical Understanding and Communicative Abilities.

\section{METHODOLOGY}

Research method that used in this research is survey. In this context, the researchers could describe some characteristics of a population whether those related to attitudes, behavior or other social as pects [24].

In the survey, data collecting process and social data analysis were definitely structured and in detail through questionnaire as major instrument to get information from some respondents who were assummed to represent a population specifically [25] .

The researchers applied survey as the instrument of collecting data by submitting questionnaire to the respondents, i.e. the adolescents/students of some vocational high schools in South Tangerang, i.e. SMK Negeri 1, SMK Negeri 2 and SMK Negeri 3 concerning the media literacy on the uses of social media (Facebook and Instagram) among adolescents. Total population of the adolescents/students of SMK Negeri 1, SMK Negeri 2 and SMK Negeri 3 amounted to 368 people. The sampling technique in this research was purposive sampling. The technique covered those who were selected in the criteria and those who did not have the criteria would be excluded from the sample [25]. The technique of Purposive Sampling was usually used in the qualitative research because it gave priority to the depth of data. However, the researchers used the technique because we intended to take sample with the criteria of the adolescents/students of SMK Negeri 1, SMK Negeri 2 and SMK Negeri 3 Tangerang who had accessed Internet/Social Media with total amount of over 8 hours per day.

\section{Sampling Technique}

The measures of sampling technique were the stipulation of population characteristics that became the target and would 
be represented by the research sample for the adolescents/ students of some vocational high schools in South Tangerang, i.e. SMK Negeri 1, SMK Negeri 2 and SMK Negeri 3.

The researchers used Slovin's formula because total population was less than 1,000 respondents. Slovin's formula was used to determine sample size of the population in which total number of the respondents had been known.

\section{Slovin's Formula}

To determine the sample size of the population that is known from the total respondents, we use Slovin's Formula:

$$
\begin{gathered}
n=\frac{N}{1+N e^{2}} \\
n=\frac{368}{1+368(0.05)^{2}} \\
n=\frac{368}{1+0.92} \\
n=\frac{368}{1.92}
\end{gathered}
$$

$191.666 \approx 192$ respondents

Notes:

$$
\begin{array}{ll}
\mathrm{n} & =\text { sample size } \\
\mathrm{N} & =\text { population size } \\
\mathrm{e} & =\text { allowance for inaccuracy due to }
\end{array}
$$
tolerable sampling errors, for example 5\% and then the e squared.

The tolerable sampling errors cannot be the same in each population. There is $1 \%, 2 \%, 3 \%, 4 \%, 5 \%$ or $10 \%$ [25]. Of the description, total samples in the population amount to 192 adolescents who had used social media (Facebook and Instagram).

\section{Operationalization of Concept}

"The research variables are basically all kinds of form that the researchers have decided to study so that they can get information on the research data, and therefore, they can make conclusion" [24]. In this research, there is one variable, i.e. independent variable for which the variable is measurable, it should be defined in its operationalization as follows.

Fig.2: Operationalization of Concepts

\begin{tabular}{|l|l|l|}
\hline Variables & Subvariables & Indicators \\
\hline $\begin{array}{l}\text { Literacy of } \\
\text { Media }\end{array}$ & Use Skill & $\begin{array}{l}\text { a. reading books (print or e } \\
\text { book); } \\
\text { b. reading news papers } \\
\text { (print or online); }\end{array}$ \\
& & $\begin{array}{l}\text { c. playing computer or } \\
\text { games; }\end{array}$ \\
& & d. using internet; \\
& & e. sending data \\
\hline
\end{tabular}

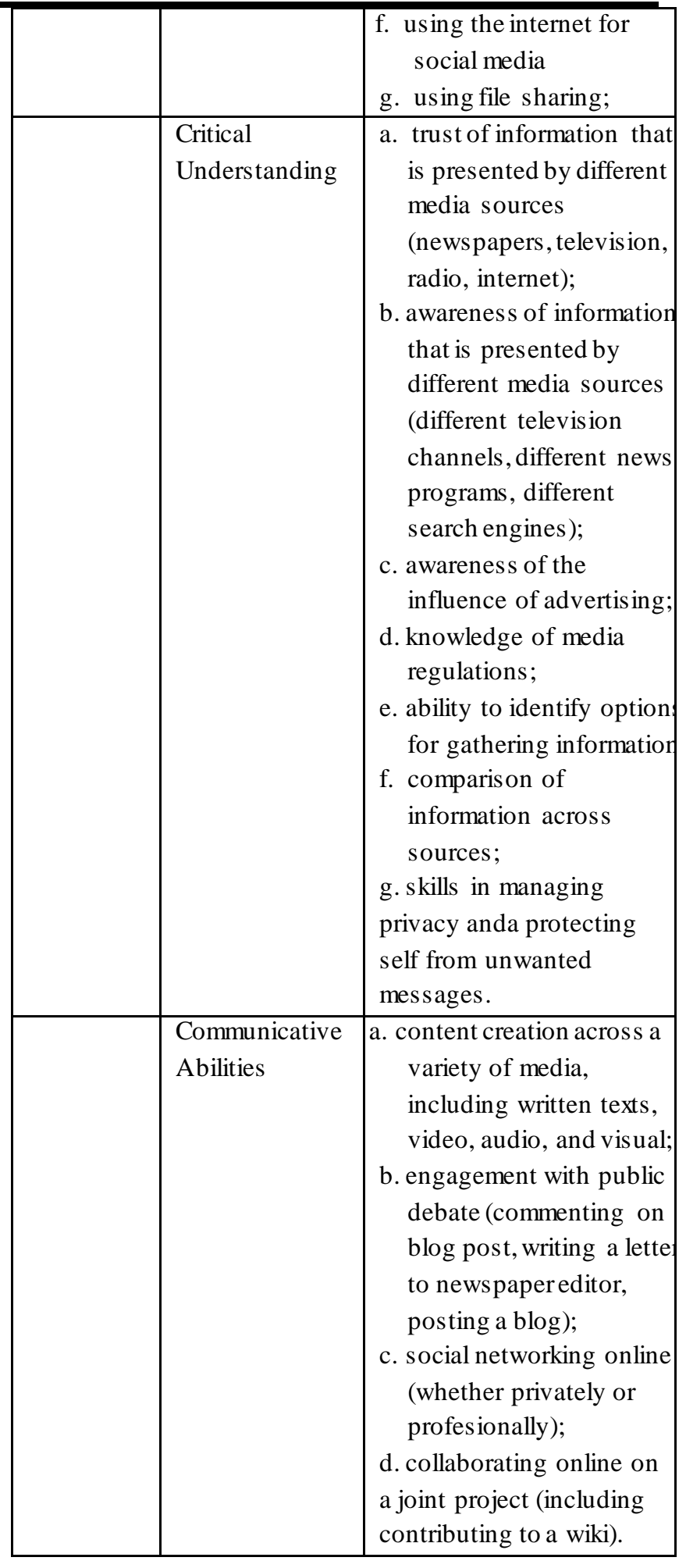

\section{FINDINGS AND DISCUSSION}

Based on the data it can be concluded that the Media Literacy Levels on the uses of social media among adolescents/ students is quite good. Quite good means that it bases on the statistical data processing results of frequency distribution, it indicates that media literacy level among adolescents in the uses of social media is in the medium category. 
Fig.3: Distribution Frequency of Media Literacy Levels Among Adolescents in South Tangerang

\begin{tabular}{|c|c|c|c|}
\hline Interval & Categories & $\mathbf{F}$ & $\mathbf{( \% )}$ \\
\hline $95-106$ & Basic & 57 & $31.03 \%$ \\
\hline $107-118$ & Medium & 92 & $48.28 \%$ \\
\hline $119-130$ & Advanced & 43 & $20.69 \%$ \\
\hline \multicolumn{2}{|c|}{ Total } & 192 & $100 \%$ \\
\hline
\end{tabular}

Source: Results of Processed Primary Data, 2018

Based on Table 2, it is known that of 192 respondents in the research sample, 27 respondents $(31.03 \%)$ were in the low level with the value range between 95-106. Moreover, 42 respondents (48.28\%) were in the middle level with the value range between 107-118. Finally 18 respondents $(20.69 \%)$ were in the high level with the value range between 119-130. From the above data, it can be concluded that the media literacy level for adolescents/ students in majority in the middle level with total value between 107-118, and 92 respondents of total 192 respondents could reach $48.28 \%$.

In relation to the media literacy model having been classified in the Individual Competence Framework oleh European Commission in Final Report Testing and Refining Criteria to Assess Media Literacy Levels in Europe 2009, there are three indicators related to the measurement of the media literacy levels, i.e. Use Skills, Critical Understanding and Communicative Abilities.

From the data presentation at above, the basis of the media literacy levels that has been stated in the European Commission Directorate General Information Society and Media; Media Literacy Unit, 2009, i.e. Basic, Medium and Advanced Level indicates that the media literacy level for the users of social media in adolescents / students in the medium category. As stated in European Commission Directorate General Information Society and Media; Media Literacy Unit 2009, individuals are clever to use media, know their functions and are able to carry out more complex oepration (Use Skills). The users know how to get and value information they need and evaluate (and increase the strategy of information searching) (Critical Understanding) and actively produce media content and participation socially (Communicative Abilities).

There are some characteristics of each indicators in making the media literacy levels on the uses of social media as follows:

\section{Use Skill}

Of three indicators of making the media literacy level in this research, the highest score came from the indicators of the Use Skill with average value of 36.38 and the highest value is 45 with total percentage of $60.92 \%$. Therefore, it entered the medium category. The Use Skill was the technique skill to use media. It meant that individuals were able to operate media and understand all kinds of instructions in the media.

The Use Skill itself had two sub-indicators, i.e. the Ability to use media technically and the Understand Instructions and the purposes of media uses. When we saw the Sub-Indicators of the ability to use media technically, the respondents had the medium level with total value of $70.1 \%$ and the value achievement between 19-23 and the highest value of 29. The number showed that the ability level to use social media in a kind of operating social media was quite good. It meant that the media literacy that the respondents had in operating and use media with the medium category was not too basic or too advanced.

In the category of literacy ability having stated by Rianto (2018), it covered alphabetical, representational and tool literacy, and therefore, it could explain that the respondents had had good tool literacy ability. As having been stated in the theory, Rianto (2018) stated that the tool literary was the technical literary and it related to the uses of technology and computer so that they knew what knowledge (declarative), how (procedural) and when, where, why and in what condition (conditional).

Considering the above condition, the respondents procedurally had a relatively good ability. It meant that with the skill in this matter they operated the uses of social media or consumed social media. They had carried out selectivity process particularly the setting of corect place and way so that they could retrieve the media content they consumed in relation to how to deveop their skill as a clever user in media, such as the media uses operationally.

In relation to the uses of social media, based on the above analysis, it can be concluded that the respondents are relatively able to choose, select and send as well as understand the uses of social media. In other words, they can select accurate media content to be consumed so that they can avoid the consumption of negative content.

In the sub-indicators of understanding Instructions and the purposes of media uses as shown in the condition of the respondents, the position of understanding the purposes of media uses indicate the basic category with total value of 20.7 , the medium one of $52.9 \%$ and the advanced one of $26.4 \%$. Of the data findings, it means that as the users of social media they have a relatively good consciousness of understanding instruction in the media and access social media only for the purpose. It is quite good and it indicates that they understand the purposes of using social media in the medium level, so that the value is not too high or not too low. Therefore, it can encourage them to control themselves in taking everything they consume through 
social media. It can be shown in the ability to understand media uses, the majority is only in the medium level or quite good. This bases on their awareness of using social media which automatically gives control to filter messages and provide meaning in the context.

The above statements will correct the theory that has been stated by Potter (2018) that media literacy is a skill to make screen in selecting and choosing the content of message in media whether it is print or electronic media.

\section{Critical Understanding}

If compared to the indicators of Use Skill, the indicators of Critical Understanding were not too different. These had average score of 47.85 with the percentage of $51.72 \%$. Therefore, it was in the medium category. It meant that the difference between the indicators of Use Skill and the Critical Understanding was only $9.2 \%$. The Critical Understanding itself was the main indicators to know the media literacy level. The indicators tried to measure the users' ability to use social media cognitively, to start understanding, analyzing and evaluating the media content they consume. Based on the acquisition of total score or categorization of the media literacy level from the Critical Understanding indicators itself, the ability the respondents have to understand, analyze and evaluate the use of social media is quite good or in the medium level.

From the category of media literacy ability as stated by Rianto (2018), the indicators of the Critical Understanding became the type of the representational literacy, i.e. the information analysis ability so as to understand the meaning of the content. The ability to understand and analyze the media content from the respondents was quite good and it was closely related to the position of the students who were focused on the field related to media and communication. In this matter, they provide more provisions to get to know the performance of the media industry. Different from outside of the similar field, it does not have relations with such provisions, their critical level of the media content is not necessarily quite good.

In the Critical Understanding indicator itself has four sub indicators including Ability to provide trust in information presented by various media sources, Awareness of media use in understanding information presented by various media sources, Ability to identify options for gathering information and Skills in managing privacy and protecting yourself from unwanted messages.

From the sub-indicators of ability to have trust to the information presented in various media sources, it was in the medium level of $60 \%$. Moreover, the awareness level of media uses to understand information presented in various media sourcess reached $51 \%$ or it was in the medium category. It showed that the characteristics of the media literacy level were high, the respondents were able to identify options for gathering information from various media sources. The research findings showed the achivement score at $51 \%$ or the advanced category. Concerning the research findings on the ability to identify options for gathering information, the basic category of the sub-indicators was only $8 \%$ and the majority was only in in the advanced or medium level. This based on the awareness of social media uses and otherwise it would give control to filter messages and provide meaning in the media uses.

Furthermore, it related to the sub-indicators of skill to manage privacy and protect themselves from unwanted messages. In fact the respondents included in the medium level or quite good in this matter. For example, they stated that Facebook and Twitter provided access settings for account users to block unwanted messages and provided communication services privately. Around $82 \%$ of the respondents said "not infrequently" when they set to block notifications or other users when they found unwanted messages or users.

From the achievement score for the indicators of the Critical Understanding at above, it can be concluded that the respondents have media literacy skill in the ability to criticize media analytically, reflexively and ethically. As revealed by Christ \& Potter (1998), the ability to criticize media is divided into three categories of behavior, i.e. the analytical category from which the respondents understand problems in social processes such as the concentration of media ownership, reflexive ability to apply knowledge analytically for themselves or actionally and ethically, i.e. the dimensions of combined analytical and reflexive thinking that show social awareness in which as the users of social media whose scope includes social community, the respondents' awareness to manage digital information is easily disseminated through social media.

\section{Communicative Abilities}

The indicators of Communicative Abilities were directed to see the ability of audiences to make socialization and media participation. From the results of data analysis, it showed that average value for Communicative Abilities reached medium media literacy level. It meant that the respondents in the ability of socialization and participation or their active ability to use social media in media were quite good or not too advanced or too basic.

Besides the two indicators at above, if compared to the indicators of Use Skills and Critical Understanding, the indicators of Communicative Abilites were in the 
lowest value if compared to the others. The value achievement from the indicators of communicative abilites reached average value of 27.34 with percentage of $59.77 \%$. It meant that their abilities of producing media content and social participation were less able to create positive content in social media.

The communicative abilities themselves in this research have three sub-indicators, i.e. understanding in participation in the content making of various media such as written text, video, audio and visual. The involvement in public debate in a media and Involvement in social network relationships.

Concerning the indicators of Communicative Abilities, the highest score the respondents get when they involve in social network relationships amounts $68 \%$. In relation to the uses of social media, some respondents not only have relatively adequate information and follow the information but also they are involved in social media relationship whether it is personally or not. The attitude indicates that the respondents are classified into adolescence. As stated by Gourlay et al., (2014), adolescence starts growing the self of adolescents to stimulate their life, the need of friends who can understand and support them, friends who can sympatize with their happiness and sadness. This period partly looks for something that can be considered valuable, deserve to be held in high esteem and adored so that it can be called the period of longing for adoring (deification), i.e. the instability of adolescents.

Moreover, the second score for the indicators of Communicative Abilities, i.e. the involvement in public debate of a media is in the medium level with total value of $64 \%$. It can be concluded that the respondents consciously make interaction, communication or public debate as the response to some messages through social media.

Moreover, for the indicators of understanding in participation on the content making in various media including written text, video, audio and visual if compared to other sub-indicators, the sub-indicators are smaller in the achievement value, i.e. between 7-8 for $59 \%$. However, it remains in the medium level or it is quite good. It means that they are able to create positive content to be exposed through social media.

As stated by Potter (2018), the media literacy is a perspective where we can actively show our self ability to expose in media and interpret the meaning of messages we find.

\section{CONCLUSION}

According to the research findings and analysis, it indicates that media literacy rate in social media uses (Facebook and Twitter) among adolescents in Tangerang is in the middle category with the achievement score of $107-118$ from $48.28 \%$ of the respondents or 92 of total 192 respondents. The achievement score comes from three indicators as follows:

1. The indicators of Use Skill. These includes subindicators of skills in media uses (reading information online, sharing files/sending data, the uses of Internet in social media) and understanding the goal of media uses with average value of 36.38 that comes from $60.92 \%$ and it enters into the middle category.

2. The indicators of Critical Understanding that measure the cognitive skills of adolescents in media uses such as skills of understanding, analyzing and evaluating media content with average value of 47.85 that comes from $51.72 \%$ of the respondents and it enters into the middle category.

3. The indicators of Communicative Abilities are directed to measure adolescents' skills to make socialization and participation in social media. In these indicators it reaches media literacy rate in the middle category. Out of the previous two indicators if compared to the indicators of Use Skills and Critical Understanding, the indicators of Communicative Abilities become the lowest ones. The achievement score that the indicators of Communicative Abilities only reaches 27.34 of $59.77 \%$ in average. It means that with their skills they could not produce media content and social participation when they create positive content in social media.

\section{ACKNOWLEDGEMENTS}

We would like to show our gratitude to the research centre at Universitas Mercu Buana, the Ministry of Research Technology and Higher Education and to the independent reviewers who conducted a feasibility study of our research work.

\section{REFERENCES}

[1] D. J. Atkin, D. S. Hunt, and C. A. Lin, "Diffusion theory in the new media environment: Toward an integrated technology adoption model," Mass Commun. Soc., vol. 18, no. 5, pp. 623-650, 2015.

[2] G. R. Adiarsi, Y. Stellarosa, and M. W. Silaban, "Literasi media internet di kalangan mahasiswa," Humaniora, vol. 6, no. 4, pp. 470-482, 2015.

[3] P. Rianto, "Media Baru, Visi Khalayak Aktif dan Urgensi Literasi Media," J. Komun. Ikat. Sarj. Komun. Indones., vol. 1, no. 2, pp. 90-96, 2018.

[4] M. E. Len-Ríos, H. E. Hughes, L. G. McKee, and H. N. Young, "Early adolescents as publics: A national survey of teens with social media accounts, their 
media use preferences, parental mediation, and perceived Internet literacy," Public Relat. Rev., vol. 42, no. 1, pp. 101-108, 2016.

[5] R. Hobbs, "Measuring the digital and media literacy competencies of children and teens," in Cognitive development in digital contexts, Elsevier, 2017, pp. 253-274.

[6] M. Thomas, Deconstructing digital natives: Young people, technology, and the new literacies. Taylor \& Francis, 2011.

[7] L. Dogruel, S. Joeckel, and N. D. Bowman, "The use and acceptance of new media entertainment technology by elderly users: Development of an expanded technology acceptance model," Behav. Inf. Technol., vol. 34, no. 11, pp. 1052-1063, 2015.

[8] D. Giles, Psychology of the media. Macmillan International Higher Education, 2010.

[9] T. Kesler, P. P. L. Tinio, and B. T. Nolan, "What's our position? A critical media literacy study of popular culture websites with eighth-grade special education students," Read. Writ. Q., vol. 32, no. 1, pp. 1-26, 2016.

[10] J. Kahne, N.-J. Lee, and J. T. Feezell, "Digital media literacy education and online civic and political participation," Int. J. Commun., vol. 6, p. 24, 2012.

[11] Y. L. C. Reid, J. Radesky, D. Christakis, M. A. Moreno, and C. Cross, "Children and adolescents and digital media.," Pediatrics, vol. 138, no. 5, 2016.

[12] S. A. Rains, E. B. Peterson, and K. B. Wright, "Communicating social support in computermediated contexts: A meta-analytic review of content analyses examining support messages shared online among individuals coping with illness," Commun. Monogr., vol. 82, no. 4, pp. 403-430, 2015.

[13] M. Workman, "New media and the changing face of information technology use: The importance of task pursuit, social influence, and experience," Comput. Human Behav., vol. 31, pp. 111-117, 2014.

[14] N. A. Dwityas and R. Briandana, "Social Media in Travel Decision Making Process," Int. J. Humanit. Soc. Sci., vol. 7, no. 7, pp. 291-292, 2017.

[15] D. Wardhani, S. Hesti, and N. A. Dwityas, "Uses and Gratifications of Social Media: Media Use Among University Students in Jakarta," Int. J. Commun. Reserach, vol. 9, no. 1, pp. 23-31, 2019.

[16] L. Gourlay, M. Hamilton, and M. R. Lea, "Textual practices in the new media digital landscape: messing with digital literacies," Res. Learn. Technol., vol. 21, no. 4, 2014.

[17] L. DeNardis and A. M. Hackl, "Internet governance by social media platforms," Telecomm. Policy, vol.
39, no. 9, pp. 761-770, 2015.

[18] R. Hobbs, Digital and Media Literacy: A Plan of Action. A White Paper on the Digital and Media Literacy Recommendations of the Knight Commission on the Information Needs of Communities in a Democracy. ERIC, 2010.

[19] W. J. Potter, Media literacy. Sage Publications, 2018.

[20] H. Vandebosch and K. Van Cleemput, "Defining cyberbullying: A qualitative research into the perceptions of youngsters," CyberPsychology Behav., vol. 11, no. 4, pp. 499-503, 2008.

[21] R. Hobbs, "The state of media literacy: A response to Potter," J. Broadcast. Electron. Media, vol. 55, no. 3, pp. 419-430, 2011.

[22] M. Anderson and J. Jiang, "Teens, social media \& technology 2018," Pew Res. Cent., vol. 31, 2018.

[23] D. Natharius, "The more we know, the more we see: The role of visuality in media literacy," Am. Behav. Sci., vol. 48, no. 2, pp. 238-247, 2004.

[24] M. Sugiyono, "Metode Penelitian Kuantitatif, Kualitatif, dan Kombinasi,” Bandung Alf., 2012.

[25] R. Kriyantono, Teknik praktis riset komunikasi. Prenada Media, 2014.

[26] W. G. Christ and W. J. Potter, "Media literacy, media education, and the academy," J. Commun., vol. 48, no. 1, pp. 5-15, 1998. 